\title{
QUALITY ASSURANCE PELAYANAN GIZI DI PUSKESMAS KOTA BANDUNG
}

\author{
Suparman ${ }^{1}$; Nelly Olifa llyas ${ }^{1}$ dan Ichwanuddin ${ }^{1}$ \\ 'Jurusan Gizi Politeknik Kesehatan Bandung
}

\begin{abstract}
QUALITY ASSURANCE OF HEALTH CENTER'S NUTITION SERVICES IN BANDUNG

A cross-sectional study of quality assurance of nutrition services was conducted in all (68) health centers in Bandung. Subjects selected for the study were nutrition staff, maternal and child health staff for health provider, pregnant mothers, and mother of under five years old visiting health center for consumer. Nutrition service performance, as the dependent variable, was measured by using 11 different working activities in nutrition services. Three independent variables associated with performance were collected i.e. nutrition education and training, availability of working guidebook and other facilities, and client satisfaction and complain. The study showed that there was no significant association between nutrition service performance and nutrition education and training. A significant association was found between unavailability of working guidebook and service performance. There was no association between service performance and satisfaction except for client compliance. Nutrition services performance varied widely among nutrition service providers.
\end{abstract}

Keywords: quality assurance, nutrition services, health staff

\section{PENDAHULUAN}

$\mathrm{M}$ eningkatnya permintaan akan pelayanan kesehatan khususnya di puskesmas sejalan dengan semakin terbatasnya kemampuan masyarakat untuk mengakses unit-unit pelayanan swasta, dan puskesmas telah menjadi tumpuan utama akan pelayanan kesehatan. Namun demikian pelayanan kesehatan di puskesmas sendiri masih dihadapkan pada masalah yang berkaitan dengan kualitas pelayanan.

Keberhasilan program gizi salah satunya yang sangat strategis ditentukan oleh konsistensi kualitas pelayanan yang diberikan di unit-unit pelayanan kesehatan. Walaupun strategi pembangunan kesehatan diarahkan untuk peningkatan mutu pelayanan kesehatan, namun strategi tersebut dalam operasionalisasinya lebih metitikberatkan pada aspek-aspek cakupan pelayanan (services coverage) seperti cakupan penimbangan (D/S), cakupan pemberian kapsul vitamin $A$, tablet tambah darah, dan kapsul yodium serta cakupan balita gizi buruk. Sehingga hal-hal yang berkaitan dengan kualitas pelayanan (services quality) seperti penerapan prosedur pelayanan, perubahan perilaku, kepatuhan serta "kepuasan" klien bahkan dampak pelayanan (impact of services) masih kurang diperhatikan.

Mutu pelayanan puskesmas, termasuk pelayanan gizi sangat bervariasi antar puskesmas dan banyak ditentukan oleh faktor petugas (kemampuan dan motivasi) dan sebagian lagi oleh faktor sumber daya lainnya ${ }^{(1)}$.

Penerapan pelayanan gizi di puskesmas dirasakan belum optimal, salah satu faktor karena belum adanya keseragaman dalam pelayanan gizi itu sendiri. Keadaan ini terjadi karena kualifikasi petugas yang memberikan pelayanan gizi masih terbatas dan beragam 
latar belakang pendidikan serta belum digunakannya konsep quality assurance dalam pelayanan gizi. Tidak standarnya faktor-faktor yang digunakan dalam suatu jasa pelayanan, memberikan peluang terjadinya gangguan dalam mencapai tuntutan pelayanan yang berkualitas ${ }^{(2)}$.

Penelitian ini bertujuan untuk melakukan kajian mengenai kinerja pelayanan gizi puskesmas dengan pendekatan quality assurance (jaminan kualitas), khususnya ingin mengetahui peranan faktor pendidikan dan pelatihan petugas, pedoman pelayanan terhadap penerapan quality assurance dan pengaruhnya terhadap kepatuhan dan kepuasan klien.

\section{BAHAN DAN CARA}

Disain penelitian ini menggunakan jenis survei potong lintang (cross-sectional), semua variabel-variabel penelitian diukur dan dikumpulkan secara serentak pada saat yang bersamaan. Populasi adalah seluruh puskesmas se-Kota Bandung yang berjumlah 68 buah puskesmas. Seluruh populasi puskesmas yang ada di Kota Bandung diambil sebagai sampel. Pada penelitian ini unit sampel adalah puskesmas, sedangkan unit pengamatan terdiri dari: dua petugas untuk masing-masing puskesmas terdiri dari Tenaga Pelaksana Gizi (TPG) dan Tenaga Pelaksana Kesehatan Ibu dan Anak (KIA) serta tiga ibu hamil dan tiga ibu balita. Penentuan ibu hamil dan ibu balita yang dijadikan sampel secara purposive dengan kriteria memiliki tingkat pendidikan SLTA keatas.

Variabel penelitian terdiri dari variabel independent (diklat petugas dan pedoman pelayanan gizi), variabel dependent (kinerja pelayanan gizi terdiri dari 5 jenis pelayanan gizi dan 6 jenis pengukuran antropometri) dan variabel outcome (kepuasan dan kepatuhan klien terdiri dari 20 macam pertanyaan). Variabel diklat petugas dan pedoman pelayanan gizi dan kinerja pelayanan gizi menggunakan skala ordinal 2 kategori, sedangkan kepuasan dan kepatuhan klien menggunakan skala five point Likert. Data diklat dikumpulkan dengan wawancara, sementara data pedoman pelayanan gizi menggunakan daftar tilik. Sedangkan data kinerja pelayanan gizi dilakukan dengan pengamatan (observasi dan simulasi) menggunakan daftar tilik, serta data kepuasan dan kepatuhan klien dengan wawancara $^{(3,4)}$. Uji statistik menggunakan uji non parametrik "Mann-Whitney" ${ }^{(5,6)}$.

\section{HASIL DAN BAHASAN}

\section{Tugas Pokok dan Pengalaman Kerja Sampel}

Wawancara dilakukan pada 68 orang petugas Tenaga Pelaksana Gizi (TPG) dan 68 orang Tenaga Pelaksana Kesehatan Ibu dan Anak (KIA). Sedangkan sampel ibu hamil dan ibu balita masing-masing sebanyak $184 \mathrm{ibu}$.

Hasil wawancara pengalaman kerja petugas baik tugas pokok sebagai Tenaga pelaksana Gizi maupun Tenaga KIA mendapatkan waktu yang sama yaitu ratarata selama 12 tahun.

Salah satu masalah dalam quality assurance adalah keragaman atau besarnya variasi kinerja petugas atas setiap pelayanan. Penelitian yang dilakukan terhadap sejumlah fasilitas pelayanan di Amerika Serikat menunjukkan bahwa terjadi perbedaan kualitas pelayanan baik antar petugas, antar pedoman maupun antar institusi $i^{(7)}$. Hasil yang sama pada penelitian ini menunjukkan kecenderungan yang tidak berbeda jauh.

Hasil penelitian ini menunjukkan bahwa dalam satu jenis pendidikan, kinerja petugas bervariasi $(p<0.05)$, demikian juga antar pendidikan yang berbeda maupun antar pedoman $(p<0.05)$.

Penelitian ini juga menunjukkan bahwa kinerja petugas puskesmas dalam memberikan pelayanan kesehatan masih jauh dari harapan konsep quality assurance. Padahal hakaket atau tujuan quality assurance pada dasarnya adalah dihasilkannya pelayanan yang seragam oleh unit-unit pelayanan ${ }^{(8)}$.

Pengukuran kinerja pelayanan gizi 
Menurut Gambar 1, kinerja 11 pelayanan gizi yang diukur menunjukkan skor pencapaian yang bervariasi. Terdapat 7 $(63,6 \%)$ pelayanan gizi yang pencapaiannya cukup tinggi $(\geq 80 \%)$, namun masih ada sebanyak $4(36,4 \%)$ pelayanan gizi masih rendah $(<80 \%)$. Bila dianalisis, ternyata pelayanan gizi yang pencapaian kinerjanya tinggi merupakan jenis kegiatan yang biasa dilakukan, namun kurang membutuhkan ketelitian dan persiapan oleh petugas puskesmas itu sendiri.

Pada penimbangan berat badan balita hanya 4 langkah (dari 9 langkah yang ada) pengukuran yang dilakukan dengan lengkap dan benar oleh semua puskesmas. Langkah pelayanan yang jarang dilakukan, salah satunya yaitu tidak menyeimbangkan dacin dengan pemberat, sehingga hasil penimbangan berat badan balita akan cenderung lebih berat dari yang seharusnya.

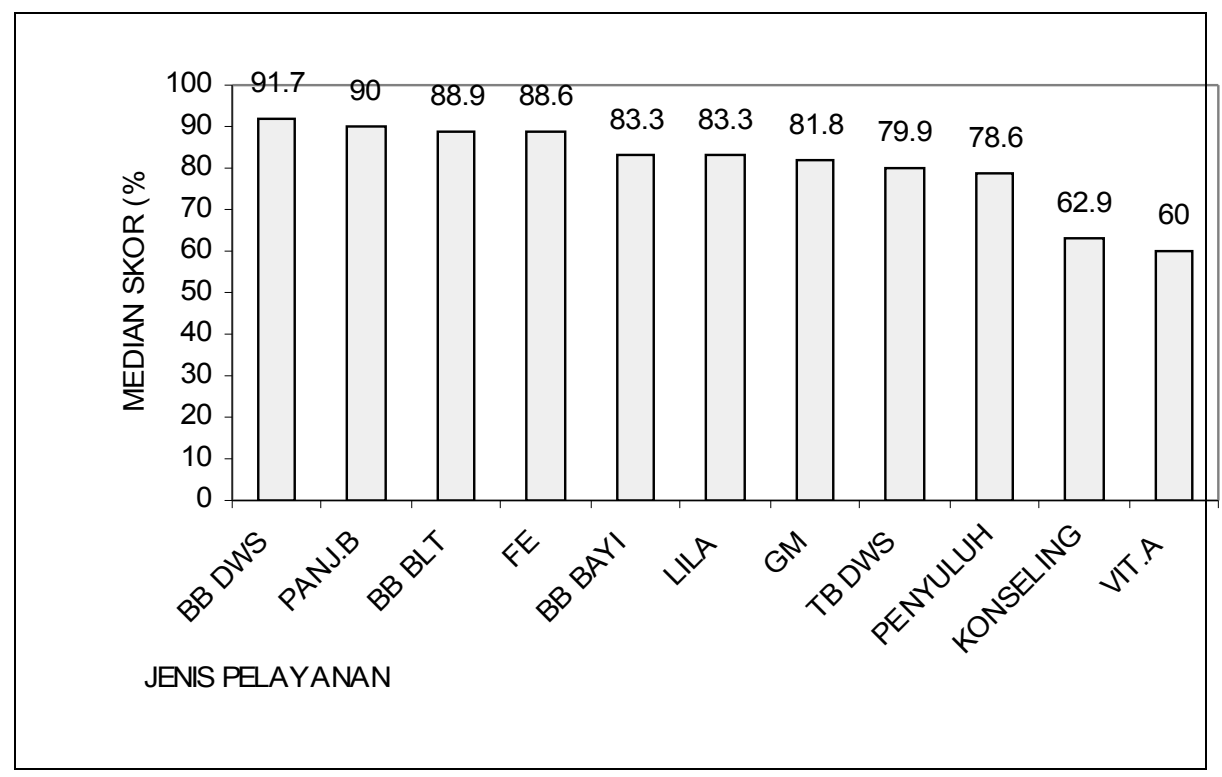

Gambar 1

Kinerja 11 Pelayanan Gizi Puskesmas

Ada pelayanan yang cukup penting dan biasa dilakukan tapi rendah pencapaiannya seperti: pengukuran tinggi badan orang dewasa, penyuluhan, pemberian kapsul vitamin A. Demikian halnya dengan pelayanan konseling gizi yang baru dilakukan oleh beberapa puskesmas tertentu (yang pernah mendapat pelatihan pelayanan Pojok Gizi), walaupun memperlihatkan kinerja yang berbeda antara petugas (petugas gizi lebih baik) namun masih harus ditingkatkan. Hal ini menunjukkan bahwa pelayanan gizi yang memerlukan persiapan dan kecermatan kurang mendapat perhatian, petugas masih sekedar memberikan pelayanan tanpa memahami prinsip dan prosedur tetap pelayanan yang diberikan.

Belum adanya perbedaan kinerja antara petugas gizi dengan petugas lain, menunjukkan bahwa ketrampilan teknis dalam melaksanakan pelayanan gizi kurang dipraktekkan. Hal ini bisa terjadi karena petugas gizi selama ini lebih banyak mengelola administrasi program gizi atau program lainnya yang cukup menyita waktu dan kesempatan, sehingga kurang mempraktekkan dan melatih kompetensi 
keprofesiannya pada pelayanan-pelayanan kegizian.

\section{Hubungan pendidikan dan latihan dengan kinerja pelayanan gizi.}

Sebagian besar sampel adalah petugas dengan latar belakang pendidikan non gizi $(69,3 \%)$ umumnya dengan pendidikan bidan, dan hanya 13 petugas $(11,4 \%)$ dengan pendidikan D-III Gizi.

Partisipasi petugas dalam pelatihan gizi, sangat diperlukan dalam pemantapan dan pengembangan program atau pelayanan gizi di puskesmas. Ternyata sebagian besar petugas tidak pernah mendapatkan pelatihan teknis gizi $(66,7 \%)$ dan hanya 21,1 persen saja yang dalam 3 tahun terakhir pernah mengikuti pelatihan teknis gizi.

Pencapaian skor diklat petugas umumnya rendah yaitu kurang dari 50 sebanyak 84 orang $(73,7 \%)$, sedangkan skor tinggi hanya sebanyak 19 orang (16,7\%). Hal ini tentunya memberikan banyak keterbatasan dalam memberikan pelayanan gizi yang standar. Ternyata latar belakang pendidikan dan partisipasi mengikuti pelatihan gizi tidak memberikan perbedaan terhadap kinerja pelayanan petugas $(P>0,05)$. Hal ini kembali membuktikan bahwa terdapat kesenjangan atau ketidakkonsistenan antara pengetahuan yang dimiliki dengan praktek pelayanan seharihari.

Pengetahuan dan pengalaman pelatihan yang dimiliki petugas, merupakan suatu hal yang belum mampu memberikan konstribusi terhadap praktek pelayanan gizi di puskesmas. Hal ini dapat terjadi karena pengetahuan dan ketrampilan yang dimiliki petugas belum diterapkan secara nyata, bisa saja diakibatkan oleh lemahnya pengawasan atau supervisi atasan dan kurangnya motivasi petugas. Profiliance atau pelaksanaan kegiatan petugas merupakan fungsi dari motivasi dan ability (9), berarti walaupun petugas memiliki ketrampilan dan pengetahuan yang cukup tentang pelayanan gizi, namun bilamana masih terjadi hambatan rendahnya motivasi kerja, maka tuntutan prosedur tetap pelayanan seringkali tidak mendapat perhatian (tidak diaplikasikan).

\section{Hubungan Pedoman Pelayanan dengan Kinerja Pelayanan Gizi}

Pedoman pelayanan gizi umumnya menunjukkan pencapaian yang cukup tinggi, tidak ada perbedaan yang sangat mencolok di antara puskesmas. Nilai median pencapaian skor 92 persen, hal ini memberikan informasi bahwa ketersediaan pedoman pelayanan gizi di puskesmas umumnya sudah baik. Analisis ketersediaan pedoman pelayanan gizi dengan kinerja pelayanan gizi petugas mendapatkan hasil adanya hubungan tetapi berlawanan $(p<0,05)$ yaitu semakin lengkap tersedia pedoman ternyata kinerja pelayanan petugas semakin menurun, hal ini dapat terjadi karena petugas belum memanfaatkan penggunaan pedoman pelayanan gizi dalam memberikan pelayanan kepada pengunjung puskesmas/ klien. Dengan pemahaman lain bahwa walaupun pedoman pelayanan gizi telah ada di puskesmas, namun pelayanan petugas masih berbeda atau tidak seragam/tidak konsisten.

Suatu penelitian yang dilakukan terhadap sejumlah praktisi pelayanan kesehatan di Boston, menunjukkan bahwa terdapat perbedaan pelayanan diantara petugas yang menggunakan pedoman yang sama (10). Sehingga peranan pedoman saja masih belum memberikan kontribusi yang positif, bilamana tidak diimbangi dengan sosialisasi pedoman dan kepatuhan petugas untuk berkerja sesuai prosedur.

\section{Hubungan Kinerja Pelayanan Gizi Dengan Kepuasan dan Kepatuhan Klien \\ Kepuasan dan kepatuhan klien} merupakan indikator dari kualitas pelayanan. Quality adalah fitness for purpose, apakah sesuatu yang diberikan itu memuaskan kebutuhan dari konsumen ke tingkat yang mereka harapkan? Hal ini menunjukkan bahwa aktifitas kerja kualitas yaitu mencocokan apa yang diharapkan (oleh klien) dengan apa yang disediakan (provider). Kepuasan klien akibat pelayanan yang baik akan menghasilkan kepatuhan klien, karena kepatuhan hanya dapat dicapai bilamana sistem 


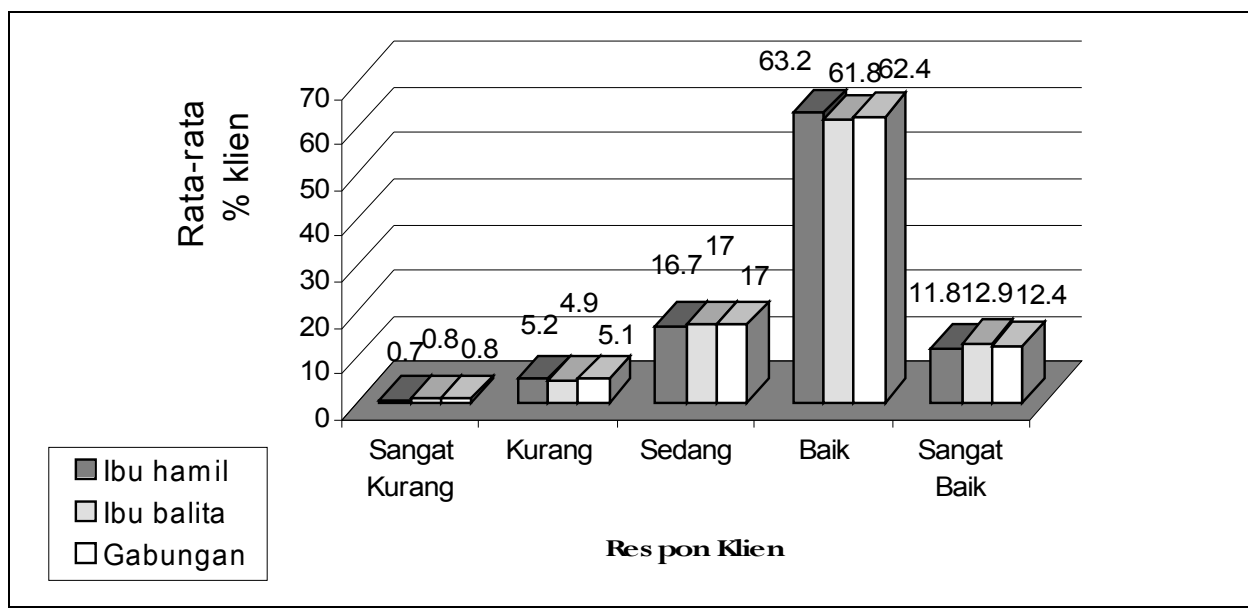

Keadaan Kepuasan dan Kepatuhan Klien Ibu Hamil dan Ibu Menyusui Terhadap Pelayanan Gizi Puskesmas

Untuk mendapatkan gambaran kepuasan dan kepatuhan dilakukan wawancara pada ibu hamil dan ibu menyusui. Hasil wawancara disajikan pada gambar 2 . Gambar menunjukkan ternyata sebagian besar klien merasa setuju dengan kualitas pelayanan (kepuasan dan kepatuhan klien) yang diberikan oleh petugas. Namun tetap harus disadari bahwa klien sebenarnya masih belum setuju bahwa pelayanan gizi yang prima telah mereka rasakan.

Dari analisis data yang diperoleh, umumnya klien menyatakan sikapnya cukup konsisten dan sebagian besar "setuju" atau cukup puas terhadap kualitas pelayanan yang diberikan oleh petugas. Namun berdasarkan hasil uji ternyata tidak ada hubungan antara kinerja pelayanan gizi dengan kepuasan dan kepatuhan klien $(p>0,05)$. Hal ini bisa terjadi walaupun ukuran kulitas kinerja pelayanan berbeda antar puskesmas, tetapi perbedaan tersebut masih direspon sama. Sikap klien kemudian bisa berbeda dengan menunjukkan jawaban ke sikap "biasa atau ragu-ragu" meningkat terhadap pernyataan yang menunjukkan kualitas pelayanan. Pernyataan-pernyataan dimaksud berhubungan dengan istilah profesional, layanan yang menyenangkan, layanan yang memenuhi keinginan, menerima layanan yang selalu baru "update" dan informasi efek samping.

Uji lanjutan terhadap hubungan kinerja pelayanan gizi dengan indikator kepuasan \& kepatuhan klien (kunjungan ulang dan informasi baru) menunjukkan hasil yang bermakna $(p<0,05)$. Respon klien bisa menjadi lebih kritis dan positif, jika kinerja pelayanan semakin baik. Puskesmas maupun petugas semakin dituntut agar mampu memberikan pelayanan yang lebih signifikan ("tidak biasa saja"). Untuk mendapatkan respon klien yang merasa puas dan merasa dilayani kebutuhannya dengan baik, agar mereka memiliki keinginan untuk kembali datang ke puskesmas atau mematuhi saran tindakan pengobatan yang diberikan, dapat ditempuh dengan meningkatkan kualitas pelayanan yang lebih unggul.

Menurut Goenari ${ }^{(11)}$, ada 4 faktor yang harus dipahami dan dilaksanakan sebelum melakukan strategi pelayanan prima:
a. memahami klien
b. memahami konsep produk
C. strategi quality improvement 
d. mengkomunikasikan standar kepada klien

Pada aspek mengkomunikasikan standar pelayanan kepada klien masih belum banyak dilakukan, sehingga pelayanan kesehatan yang berorientasi kepada klien masih harus ditingkatkan lagi melalui komitmen menarapkan konsep quality assurance pada pelayanan gizi khususnya dan pelayanan kesehatan umumnya. Demikian halnya masih sangat terbatas usaha-usaha yang dilakukan oleh staf puskesmas untuk lebih memahami produk dan jasa layanan serta dalam membuat strategi pelayanan yang lebih meningkat.

\section{KESIMPULAN}

1. Kinerja pelayanan gizi belum menunjukkan konsisten, masih bervariasi baik antar petugas, jenis pelayanan maupun pedoman pelayanan gizi yang digunakan.

2. Kepuasan dan kepatuhan klien masih belum terakomodasi oleh pelayanan petugas, walaupun umumnya klien menyatakan setuju dengan kualitas pelayanan yang diberikan, namun cukup banyak klien menyatakan raguragu manakala dikaitkan dengan tuntutan harapannya.

3. Tidak ada hubungan antara latar belakang pendidikan dan pelatihan petugas dengan kinerja pelayanan gizi $(p>0,05)$.

4. Ada hubungan berlawanan antara pedoman pelayanan gizi dengan kinerja pelayanan gizi $(p<0,05)$.

5. Tidak ada hubungan antara kinerja pelayanan gizi dengan kepuasan/ kepatuhan klien $(p>0,05)$, kecuali dengan 2 indikator kepuasan klien yaitu kunjungan ulang dan informasi baru $(p<0,05)$

\section{SARAN}

1. Langkah pertama untuk meningkatkan kualitas pelayanan gizi di puskesmas adalah melalui komitmen untuk menerapkan konsep quality assurance dengan meminimalkan bervariasinya pelayanan gizi.

2. Perlu diiventarisir jenis-jenis pelayanan gizi yang memerlukan standarisasi pelayanan dan upaya serta strategi untuk menerapkannnya.

3. Perlu dilakukan tindakan korektif (pembinaan dan supervisi) yang terus menerus kepada petugas pelayanan gizi, agar kinerja pelayanan tidak semakin jauh dari tuntutan kualitas.

\section{UCAPAN TERIMA KASIH}

Kepada tim yang terdiri dari: Siti Jamilah, Weni, Wina, Nelly, Imas, Danti, Pipit, lis, Malini, Dwihartati, Risna dan Astriana, yang telah membantu mengumpulan data ke seluruh pelosok Kota Bandung.

\section{RUJUKAN}

1. Suparman, Muslimatun $S \&$ Abikusno N.. Relationship between health centers performance and nuntrition status among children in Bandung District. Food and Nutrition Bulletin 2001, 22 (1): 39-44

2. Anderson EA, Adam DA. Evaluating the Success of TQM Implementation: Lesson from Employees. Production and Inventory Management Journal. Fourth Quarter 1997 :1-6

3. Andrzejewski N dan Laguna RT. Use of the Customer Satisfaction Survey by Health Care. Regulator : A Tool for Total Quality Management, Public Health Reports 1997. 112:206-212.

4. Jackson $\mathrm{K}$ dan Kuehn L. Using Nursing Standars to evaluate Competency. Nursing Management 1997, 28(8): 32K,32N,32P.

5. Capon J.A. Elementary Statistics for the Social Sciences. Wordsworth Publ. Co, 1988. 
6. Daniel W.W. Statistik Non Parametrik Terapan. Jakarta: Gramedia. 1989.

7. Palmer RH, Louis TA, Peterson HF, Rothrock JK, Strain R, Wright EA. What Makes Quality Assurance Effective ?. Medical Care 1996, 34 : SS29-SS39.

8. Buchara, s. \& Sukisno. Quality Assurance Guidebooks.. Jakarta : Directorate of High Education , 2000.
9. Syamsi Ibnu. Pokok-Pokok Organisasi dan Manajemen. Jakarta: Rineka Cipta, 1994.

10. Palmer RH, Wright EA, Orav EJ. Hargraves JL. dan Louis TA. Consistency in Performance Among Primary Health care Practitioners. Medical Care 1996 34:SS52-SS66.

11. Goenari A.S. Pelayanan Prima Konsep dan Strategi. Bandung : BLK, 2001. 